\title{
A point mutation in the human serum albumin gene results in familial dysalbuminaemic hyperthyroxinaemia
}

Charles E Petersen, Alfred G Scottolini, Linda R Cody, Morton Mandel, Neil Reimer, Nadhipuram V Bhagavan

\begin{abstract}
Using DNA samples obtained from two unrelated patients, diagnosed as having familial dysalbuminaemic hyperthyroxinaemia (FDH), exons 1-14 which span the entire coding region of the human serum albumin (HSA) gene were amplified by the polymerase chain reaction. The sequence of each of the 14 DNA fragments was then determined. In each case a point mutation was identified at nucleotide 653 which causes an Arg to His substitution at amino acid position 218 . The substitution was confirmed by amino acid sequencing of a mutant peptide resulting from tryptic digestion of the protein. Abnormal affinity of FDH HSA for a thyroxine (T4) analogue was verified by an adaptation of the procedure used in routine free T4 measurement. The location of the mutation is discussed in relation to other studies on the binding properties of HSA.
\end{abstract}

( $\mathcal{F}$ Med Genet 1994;31:355-359)

Department of Biochemistry and Biophysics, John A Burns School of Medicine, University of Hawaii, 1960 East-West Road, Honolulu, Hawaii Honol

C E Petersen

M Mandel

N V Bhagavan

Department of Pathology, Kaiser Foundation Hospital, 3288 Moanalua Road, Honolulu, Hawaii 96819

A G Scottolini

L R Cody

Biotechnology and Molecular Biology Instrumentation and Training Facility, Training Facility, Pacific Biomedical University of Hawaii, Honolulu, Hawaii

N Reimer Dr Bhagavan.

Received 30 July 1993 Revised version accepted for publication 17 December 1993
Familial dysalbuminaemic hyperthyroxinaemia (FDH) is an autosomal dominant syndrome in which, although patients have a raised total serum thyroxine concentration (TT4), they are clinically euthyroid. ${ }^{12}$ The euthyroid state of FDH patients is confirmed by normal serum levels of free thyroxine (FT4), thyroid stimulating hormone, and triiodothyronine. ${ }^{2}$ The prevalence of FDH has been estimated in our earlier study ${ }^{2}$ to be about $4 \%$ of hyperthyroxinaemic patients. The two FDH patients discussed in this paper are new case findings, unrelated to our previous study. ${ }^{2}$ The major hazard for FDH patients is that they can be misdiagnosed as hyperthyroid and subjected to unwarranted treatment.

The raised serum TT4 in FDH patients results from the presence of an abnormal human serum albumin (HSA) which exhibits enhanced binding to thyroxine (T4)..$^{3-8}$ Our study on intrinsic fluorescence properties of purified normal HSA and HSA obtained from an $\mathrm{FDH}$ patient, hereafter referred to as patient 1, using both steady state and time resolved methodologies, showed that the patient had two HSA species with different affinities for T4. ${ }^{9}$ Until now the specific molecular defect of FDH HSA was unknown. This study describes a specific amino acid substitution resulting from the same nucleo- tide change in the HSA gene in two unrelated FDH patients.

We have developed a rapid method for identifying FDH patients with the mutation we describe by using polymerase chain reaction (PCR) amplification of exon 7 of the HSA gene followed by restriction endonuclease digestion and gel electrophoresis.

\section{Materials and methods}

SOURCE OF WHOLE BLOOD

Whole blood drawn up in EDTA was obtained from patient 1 and patient 2, diagnosed as FDH by methods described previously. ${ }^{2}$ Whole blood was also obtained from a normal volunteer.

PURIFICATION OF NORMAL AND FDH HSA HSA was purified from the plasma of patient 1 and the normal volunteer using identical methods. Ammonium sulphate was added to the plasma to $50 \%$ saturation. HSA was precipitated from the supernatant solution by lowering the $\mathrm{pH}$ to 4.4 at $2^{\circ} \mathrm{C}$. The precipitate was dissolved in water and the lipid removed by reaction with Norit $A$ activated charcoal at $\mathrm{pH}$ 3.0 followed by dialysis in water. The HSA was further purified by affinity chromatography using cibracon blue linked to sepharose CL-6B (Sigma)..$^{10}$ The matrix was equilibrated in $0.04 \mathrm{~mol} / 1$ sodium phosphate, $\mathrm{pH} 7.5$, $0 \cdot 15 \mathrm{~mol} / 1 \mathrm{NaCl}$ (PBS). After washing the column with PBS, the bound HSA was eluted with $3 \mathrm{~mol} / \mathrm{l} \mathrm{NaCl}$. The eluent was dialysed in water. The purity of the HSA was determined by SDS-PAGE. ${ }^{11}$

\section{TRYPTIC DIGESTION OF HSA}

Purified HSA from patient 1 and purified commercial HSA (Sigma, fatty acid free, globulin free) dissolved in water were lyophylised and treated identically.

The purified HSA was reduced and alkylated to pyridyl-ethyl cystinyl HSA (PECHSA $)^{12}$ and desalted by preparative C-8 reverse phase high pressure liquid chromatography (HPLC) $(0 \cdot 1 \%$ trifluoroacetic acid to acetonitrile). The desalted PEC-HSA was digested with trypsin $(2 \%)$ in $100 \mathrm{mmol} / \mathrm{l}$ sodium bicarbonate, $2 \mathrm{~mol} / 1$ urea, $1 \mathrm{mmol} / 1$ calcium chloride, $\mathrm{pH} 8.0$ for 24 hours. The resultant peptide mixture was subjected to C18 reverse phase HPLC using a linear gradient $(0 \cdot 1 \%$ trifluoroacetic acid, $9 \%$ acetonitrile to 
$90 \%$ acetonitrile). The elution of the tryptic peptides was monitored by absorbance at $230 \mathrm{~nm}$.

An additional peak appeared in the chromatogram of the FDH PEC-HSA trypsin digest which was not present in the chromatogram of the commercial PEC-HSA tryptic digest. This peptide was collected and subjected to automated Edman degradation using an Applied Biosystems Model 477A-120 protein sequencer. ${ }^{13}$ Sequence data were confirmed by measuring the amino acid percent composition of an $\mathrm{HCl}$ hydrosylate of the peptide using a Beckman 6300 amino acid analyser. ${ }^{14}$

\section{AMPLIFICATION AND SEQUENCING OF} INDIVIDUAL EXONS

Leucocyte separation buffer $(5 \mathrm{ml})$ (Sigma, Histopaque type 1119) was layered under $15 \mathrm{ml}$ of whole blood drawn up in EDTA. Centrifugation was carried out at $400 \mathrm{~g}$ for 30 minutes. The mononuclear cell layer was collected and genomic DNA was purified (Oncor, Non-organic DNA Extraction Kit).

A set of two 24 base pair primers were chosen to be complementary to known intron DNA sequences ${ }^{15}$ on either side of each of the 14 coding exons of HSA. Fragments containing each exon were generated using PCR. For exon 7 which contains the point mutation the following oligonucleotide primers were used:

5' oligonucleotide: 5' CTGCCCTAAGGATAAGTGATTACC 3' (intron 6)

3' oligonucleotide: 5' ATTCTACCAACTTGAGCATGCAAG 3' (intron 7).

After amplification each fragment was separated from other reaction components (Qiagen, PCR Purification Spin Kit). The fragments were sequenced directly using the same primers as those used for amplification (Promega, fM Sequencing System).

All 14 exons were amplified and sequenced from genomic DNA purified from patient 1 and the normal volunteer. Corresponding termination reactions from each person were loaded next to each other in electrophoresis. The corresponding lanes were scanned for any sequence variation between the two subjects. Only exon 7 was amplified and sequenced for the second FDH patient (patient 2 ) to verify a mutation found in that exon in patient 1 .

\section{HPHI DIGESTION OF EXON 7 CONTAINING FRAGMENT}

DNA fragments containing exon 7 were generated by the same procedure used for sequencing. The fragment containing exon 7 from a normal HSA gene does not contain an $H p h I$ site whereas a mutation identified in both FDH patients creates an $H p h I$ site. The amplification product was precipitated in $75 \%$ absolute ethanol and resuspended in $20 \mu \mathrm{l}$ of $\mathrm{HphI}$ digestion buffer. Ten units of $H p h I$ (New England Biolabs) was added and the reaction was incubated for six hours at $37^{\circ} \mathrm{C}$. For each sample a control was incubated without $H p h \mathbf{I}$. Samples were electrophoresed in a 3\% agarose
(FMC BioProducts, Metaphor Agarose) gel in $1 \times$ TAE $(0.04 \mathrm{~mol} / 1$ Tris-acetate, $0.001 \mathrm{~mol} / 1$ EDTA, pH 8.0) and bands were visualised by staining with ethidium bromide.

ASSESSMENT OF HSA BINDING IN THE ABSENCE OF OTHER SERUM COMPONENTS

The binding properties of HSA from the normal volunteer and patient 1 were compared by using a radioimmunoassay kit (Clinical Assays, Stillwater, $\mathrm{MN}$ ) designed to measure the free T4 level in serum samples. Commercial HSA was also assayed as a control. The assay is designed to measure free $\mathrm{T} 4$ by competitive binding. T4 antibody is immobilised on the lower inner surface of a tube. A serum sample is added along with a fixed amount of an $\left[{ }^{125} \mathrm{I}\right] \mathrm{T} 4$ tracer. The tracer and the free T4 in the serum sample compete for binding sites on the antibody giving an inverse correlation between free $\mathrm{T} 4$ concentration and radioactivity associated with antibody.

The assay was adapted to measure HSA affinity for the T4 tracer as follows. To each assay tube $1 \mathrm{ml}$ of tracer buffer and the $\mathrm{T} 4$ tracer were added followed by $250 \mu \mathrm{g}$ of HSA in $50 \mu \mathrm{l} \mathrm{H}_{2} \mathrm{O}$. The tubes were incubated for 90 minutes at $37^{\circ} \mathrm{C}$ and the fluid was aspirated. The amount of radioactivity remaining bound to the assay tubes was measured in a Iso-Data gamma counter.

\section{Results}

AMPLIFICATION AND SEQUENCING OF PCR FRAGMENTS

DNA fragments containing exons 1-14, which span the entire coding region of the HSA gene, were successfully amplified and sequenced using genomic DNA obtained from the normal volunteer and patient 1 . The sequence obtained for the normal volunteer matched a previously published HSA sequence ${ }^{15}$ at all coding nucleotides. Sequence obtained from patient 1 matched the sequence at all positions except for a $G$ to $A$ transition at nucleic acid position 653 (fig 1) causing an $\operatorname{Arg}$ (CGC) to $\mathrm{His}(\mathrm{CAC})$ substitution at amino acid position 218 in mature HSA.

Although an adenosine appears at position 653 in the FDH sequence the guanosine is still present but at half the intensity of the corresponding guanosine in the normal sample. This indicates that the condition is heterozygous as the PCR fragment represents an amplification of both alleles. The mutation was verified by observing a $\mathrm{C}$ to $\mathrm{T}$ transition on the opposite strand (fig 1). Amplification and sequencing of exon 7 using genomic DNA obtained from patient 2 gave a result for exon 7 identical to that of patient 1 .

\section{HPHI DIGESTION OF EXON 7 CONTAINING FRAGMENT}

The exon 7 containing DNA fragments from both FDH patients were subjected to $H p h \mathrm{I}$ digestion. Only partial digestion was observed for both heterozygotes, as expected (fig 2). A 

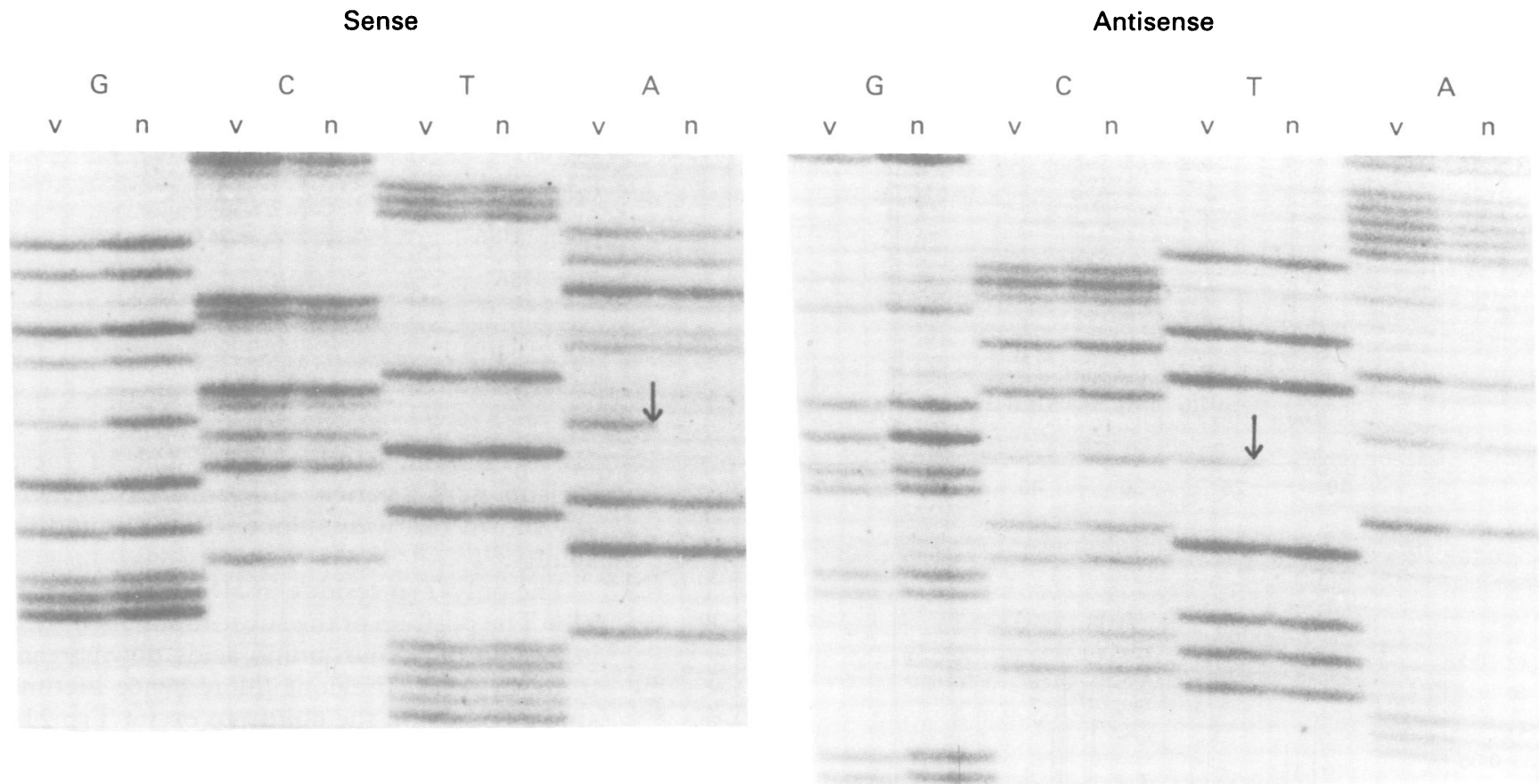

Figure 1 Alignment of normal and (FDH) sequencing termination reactions for exon 7 showing location of mutation. $G, C$, $T$, and $A$ refer to the termination reactions containing ddGTP, ddCTP, ddTTP, and ddATP respectively. Lanes labelled $(n)$ and $(v)$ indicate sequencing termination reactions for normal and variant (FDH) samples respectively. The position of the mutation is indicated by an arrow.

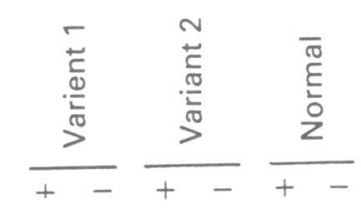

Hphl

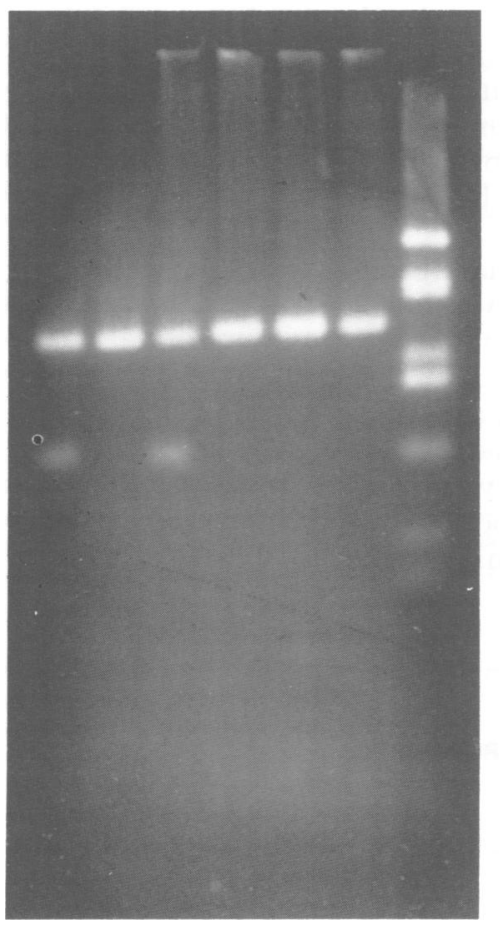

$-587$

$-434,458$

$-298$

$-257,267$

$-174$

$-102$

$-80$
Figure 2 HphI digestion of exon 7 containing DNA fragments from the normal volunteer and FDH patients 1 and 2 . Fragments from the normal person and FDH 1 and 2 . Fragments from the normal person and FDH variant 2 , respectively. The addition of $10 \mathrm{U} \mathrm{HphI}$ is indicated as +, - indicates that no HphI was added. single thick band is seen at a position corresponding to a 174 base pair marker. The size of the two fragments expected after digestion are 173 and 182 base pairs which migrate in the agarose gel as an unresolved doublet. The fragment derived from the normal volunteer is not digested by $H p h$ I.

TRYPTIC DIGESTION OF HSA

Comparison of the chromatograms derived from a tryptic digest of commercial HSA and FDH HSA clearly showed an additional peak in the FDH chromatogram (fig 3, panels A and B). Sequencing of the material from the extra peak gave a homogeneous peptide with a sequence of AWAVAHLSQR, indicating an Arg to His substitution at position 218 (fig 4). The amino acid percent composition of the peptide confirmed the above sequence.

\section{ASSESSMENT OF HSA BINDING IN THE ABSENCE} OF OTHER SERUM COMPONENTS

Adding purified HSA from the normal volunteer or commercial HSA to the T4 assay system did not significantly reduce the amount of T4 tracer associated with the T4 antibodies, relative to a standard to which no HSA was added. Adding purified HSA from patient 1 significantly reduced the amount of tracer associated with the antibodies indicating an increased affinity of the FDH HSA for the T4 tracer (table).

\section{Discussion}

The recently published high resolution $x$ ray crystallographic structure for HSA $(2.8 \mathrm{~A})^{16}$ gives an atomic structure divided into three homologous domains 1,2 , and 3 , each divided 

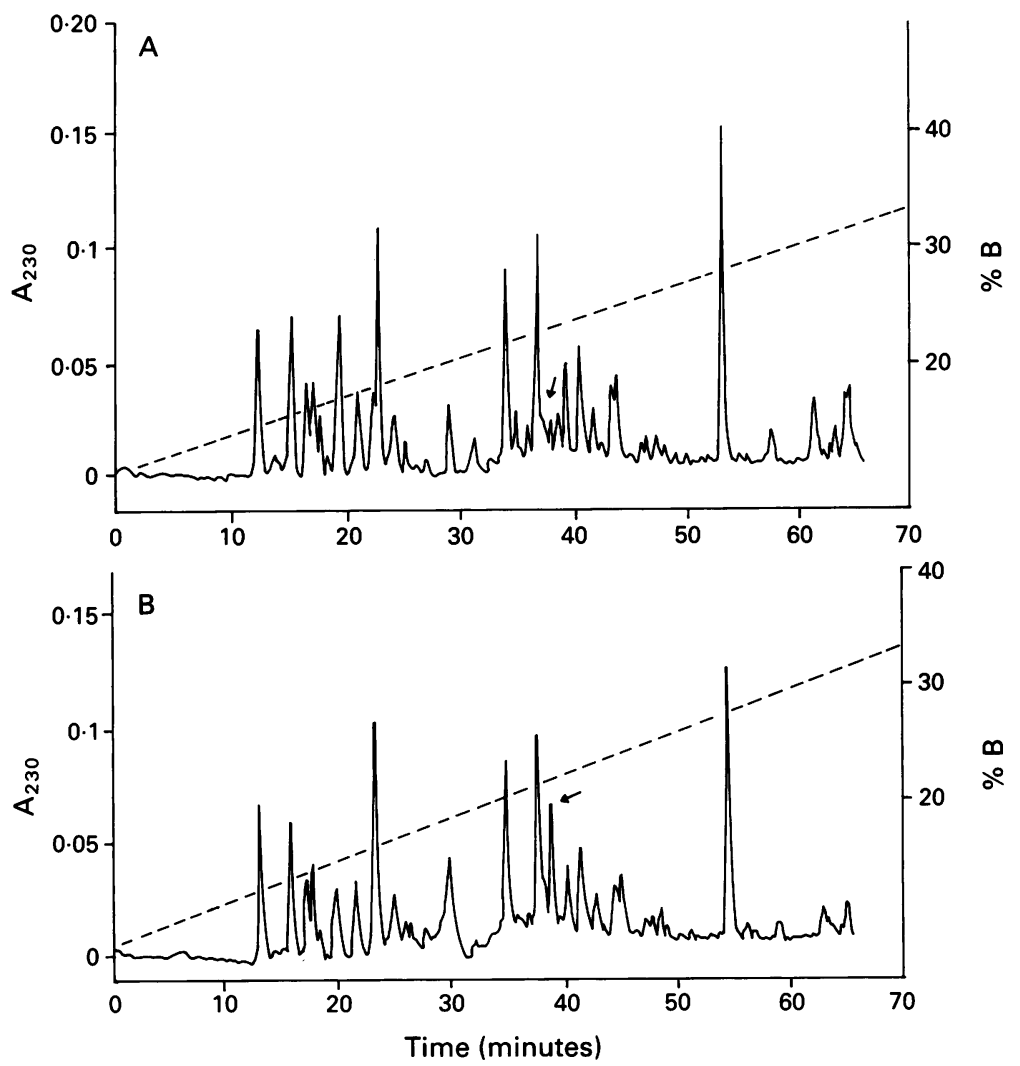

Figure 3 Chromatogram of trypsin digest of commercial HSA (panel A) and HSA purified from FDH patient 1 (panel B). The absorbance at $230 \mathrm{~nm}$ is shown on the left vertical axis. The gradient was formed by the mixing of solution $A(0 \cdot 1 \%$ trifluoracetic acid) and solution $B(0.1 \%$ trifluoracetic acid, $90 \%$ acetonitrile). The broken line shows the $\% B$ composition of the eluent, as indicated on the right vertical axis. The horizontal axis indicates the time from the start of elution. The position of the extra peak in the FDH chromatogram and the corresponding position in the commercial HSA chromatogram is shown by an arrow.

into two subdomains $\mathrm{A}$ and $\mathrm{B}$. The structure shows two principle hydrophobic binding pockets located in subdomains $2 \mathrm{~A}$ and $3 \mathrm{~A}$. $X$ ray crystallographic structures determined for HSA with a number of small hydrophobic bound ligands shows binding to occur in subdomain $2 \mathrm{~A}$ or $3 \mathrm{~A}$. The Arg to His substitution at amino acid position 218 that we have described is located in subdomain $2 \mathrm{~A}$.

A large number of HSA variants have been described by previous investigators. Almost all of these variants were identified by anomalous electrophoretic migration. ${ }^{17}$ In contrast, the variant we have identified migrates at the same position as normal HSA in native and denaturing electrophoresis gels. Interestingly, almost all of the variants that have been reported are clustered in domain 1 and subdomains $2 \mathrm{~B}$ and

Normal HSA residues (210-223)

$$
\text { AFKIAWAVAR/LSOR/F } \quad-\stackrel{\text { Trypsin }}{-}-
$$

FDH HSA residues (210-223)

\section{AFKIAWAVAHLSQR/F $\quad-$ Trypsin $\rightarrow$ AWAVAHLSQR}

Figure 4 Extra peptide expected from digestion of FDH HSA with trypsin. Trypsin cleaves proteins on the carboxyl side of Lys and Arg residues. An amino acid substitution of Arg to His at position 218 in HSA destroys a trypsin cleavage site resulting in a new peptide upon trypsin digestion of FDH HSA. The FDH substitution is shown in bold type.
Competitive binding of ${ }^{125}$ I T4 tracer with different preparations of $H S A$

\begin{tabular}{ll}
\hline Sample & $C P M^{*}$ \\
\hline No HSA & $24355 \dagger$ \\
Commercial HSA & 23669 \\
& 24423 \\
Normal HSA & 22456 \\
& 26649 \\
FDH HSA & 22798 \\
& 12426 \\
\end{tabular}

* Indicates the counts per minute remaining associated with the T4 antibodies after incubation with the HSA sample indicated. $\dagger$ All assays were carried out in duplicate.

$3 \mathrm{~B} \cdot{ }^{18-22}$ Binding studies with some of these variants with a variety of ligands have generally shown relatively minor effects on binding affinity. ${ }^{23}$

The only Trp residue in HSA is at position 214. The position of the substitution identified is located only four amino acids downstream from Trp 214. Previous fluorescence lifetime studies based on the ability to excite Trp 214 selectively using FDH HSA obtained from patient 1 have shown enhanced quenching of tryptophan fluorescence relative to $\operatorname{Trp} 214$ of normal HSA. ${ }^{9}$ This result is consistent with a substitution located relatively close to $\operatorname{Trp}$ 214.

Binding studies using HSA immobilised on sepharose have shown that thyroxine binding can be divided into a high and low affinity component. Only the high affinity component can be inhibited competitively with bilirubin. ${ }^{24}$ Bovine serum albumin has been shown to have a single high affinity bilirubin binding component which is retained by a proteolytic bovine serum albumin fragment (residues 186306) which corresponds to the $2 \mathrm{~A}$ subdomain in HSA. ${ }^{25}$ The observation that the high affinity thyroxine binding component of HSA can be competitively inhibited by bilirubin which has been localised to subdomain $2 \mathrm{~A}$ suggests that the high affinity thyroxine binding site is located in subdomain $2 \mathrm{~A}$. The amino acid substitution we have described is also located in subdomain $2 \mathrm{~A}$.

Both FDH patients in this study are heterozygous. The plasma of such persons contains a mixture of variant and normal HSA. One of our immediate goals is to obtain accurate binding constants for the variant HSA with a number of ligands. In previous binding studies a mixture of HSA species obtained from a heterozygous FDH patient was used and although the binding data were sufficient to determine heterozygosity an accurate binding constant for thyroxine could not be determined owing to the two component nature of the system. ${ }^{9}$ Attempts to separate a mixture of HSA from a heterozygote using a variety of electrophoretic and chromatographic techniques have been unsuccessful. The observation that the mixture can not be resolved by a variety of separation methods that take advantage of differences in the shape and surface structure of proteins suggests that the variation acts locally to affect thyroxine binding rather than by transmitting a change to another location in the molecule through an effect on overall structure. 
We plan to express the variant HSA in a eukaryotic expression system so that we can determine an accurate binding constant for thyroxine and other relevant ligands using a homogeneous preparation of HSA. Using site directed mutagenesis we hope to create variants in the $2 \mathrm{~A}$ subdomain with a range of binding properties for thyroxine, bilirubin, and warfarin. Warfarin binding has also been localised to domain $2 .{ }^{26}$

Having observed the same mutation in two unrelated FDH patients it is likely to be the most common cause of FDH. (During the preparation of this manuscript a third FDH patient unrelated to patient 1 and patient 2 was shown to have the same mutation by the $H p h I$ digestion method.) A point mutation in transthyretin also causes increased affinity for thyroxine leading to euthyroid hyperthyroxinaemia. ${ }^{27}$

An HSA variant with an increased affinity for thyroxine may have clinical applications for the treatment of hyperthyroidism, a disease state in which free serum thyroxine is raised. HSA or a truncated form with increased affinity for thyroxine could be given intravenously. The thyroxine would be sequestered by the HSA, rapidly lowering the free thyroxine level. We are currently working towards the development of this clinical application.

We are grateful to Stephen Swenson for help with protein purification, Thelma Oshiro for technical assistance, and Steven Seifried and Gordon Edlin for advice and helpful suggestions.

1 Ruiz M, Rajatanavin R, Young RA, et al. Familial dysalbuminemic hyperthyroxinaemia: a syndrome that can be confused with thyrotoxicosis. N Engl $f_{\text {Med }}$ confused with

2 Scottolini AG, Bhagavan NV, Oshiro T, Powers L. Familial dysalbuminemic hyperthyroxinaemia: a study of four probands and the kindred of three. Clin Chem probands and

3 Lee WNP, Golden MP, Van Herle AJ, Lippe BM, Kaplan SA. Inherited abnormal thyroid hormone-binding protein causing selective increase of total serum thyroxine. $f$ tein causing selective increase of total
Clin Endocrinol Metab 1979;49:292-9.

4 Stockigt JR, Topliss DJ, Barlow JW, White EL, Hurley DM, Taft P. Familial euthyroid thyroxine excess: an appropriate response to abnormal thyroxine binding associated with albumin. $\mathcal{f}$ Clin Endocrinol Metab 1981;53:353-9.

Docter R, Bos G, Krenning EP, Fekkes D, Visser TJ, Hennemann G. Inherited thyroxine excess: a serum abnormality due to an increased affinity for modified albumin. Clin Endocrinol 1981;15:363-71.
6 Borst GD, Premachandra BN, Burman KD, Osburne RC, Georges LP, Johnsonbaugh RE. Euthyroid familia hyperthyroxinemia due to abnormal thyroid hormonebinding protein. Am F Med 1982;73:283-9.

7 Barlow JW, Crismann JM, White EL, Funder JW, Stockigt JR. Familial euthyroid thyroxine excess: characterization of abnormal intermediate affinity thyroxine binding to albumin. $\mathcal{F}$ Clin Endocrinol Metab 1982;55:244-50.

8 Lalloz MRA, Byfield PGH, Himsworth RL. Hyperthyroxinemia: abnormal binding of thyroxine by an inherited nemia: abnormal binding of thyroxine by an il

9 Dughi C, Bhagavan NV, Jameson DM. Fluorescence investigations of albumin from patients with familial dysalvestigations of albumin from patients with familial dysal-
buminemic hyperthyroxinemia. Photochem Photobiol buminemic hyp

10 Schroeder DD. UK Patent No. 1540, 1979, 165.

10 Schroeder DD. UK Patent No. 1540, 1979, 165 . assembly of the head of bacteriophage T4. Nature 1970;227:680-5.

12 Friedman M, Krull LH, Cavins JF. The chromatographic determination of cystine and cysteine residues in proteins as S-B-(4-pyridyethyl) cysteine. $\mathcal{F}$ Biol Chem

13 Tarr GE. Improved manual sequencing methods. Methods Enzymol 1977;47:335-57.

14 Spackman DH, Stein WH, Moore S. Automatic recording apparatus for use in the chromatography of amino acids. Anal Chem 1958;30:1190-206.

15 Minghetti PP, Ruffner DE, Juang WJ, et al. Molecular structure of the human albumin gene is revealed by nucleotide sequence within q11-22 of chromosome 4 . $\mathcal{J}$ Biol Chem 1986;261:6747-57.

$16 \mathrm{He}$ XM, Carter DC. Atomic structure and chemistry of human serum albumin. Nature 1992;358:209-15.

17 Sheat JM, Peach RJ, George PM. Rapid detection and initial characterization of genetic variants of human serum albumin. Clin Chem 1991;37:1221-4.

18 Arai K, Huss K, Madison J, et al. Amino acid substitutions in albumin variants found in Brazil. Proc Natl Acad Sci USA 1989;86:1821-5.

19 Arai K, Madison J, Shimizu A, Putnam FW. Point substitutions in albumin genetic variants from Asia. Proc Nat Acad Sci USA 1990;87:497-501.

20 Arai K, Ishioka N, Huss K, Madison J, Putnam FW. Identical structural changes in inherited albumin variants from different populations. Proc Natl Acad Sci USA 1989;86:434-8.

21 Galliano M, Lorenzo M, Porta F, et al. Mutations in genetic variants of human serum albumin found in Italy. Proc Natl Acad Sci USA 1990;87:8721-5.

22 Takahashi $\mathrm{N}$, Takahashi $\mathrm{Y}$, Isobe $\mathrm{T}$, et al. Amino acid substitutions in inherited albumin variants from Amerindian and Japanese populations. Proc Natl Acad Sci USA 1987;84:8001-5.

23 Kragh-Hansen U, Minchiotti L, Brennan SO, Sugita O Hormone binding to natural mutants of human serum Hormone binding to natural mutants of

24 Kamikubo K, Sakata S, Nakamura S, Komaki T, Miura KJ. Thyroxine binding to human serum albumin immoKJ. Thyroxine binding to human serum albumin immobilized on sepharose and effects of nonprotein albumin-

25 Reed RG, Feldhoff RC, Clute OL, Peters T Jr. Fragments of bovine serum albumin produced by limited proteolysis. Conformation and ligand binding. Biochemistry

26 Bos JMO, Remjin JPM, Fischer MJE, Witling J, Janssen LHM. Location and characterization of the warfarin binding site of human serum albumin. Biochem Pharmaco 1988;37:3905-9.

27 Moses AC, Rosen HN, Moller DE, et al. A point mutation in transthyretin increases affinity for thyroxine and produces euthyroid hyperthyroxinemia. $f$ Clin Invest 1990;86:2025-33. 